tens of thousands of Henan blood donors were infected through blood transfusions. Last year the government announced a US\$150-million package to establish safe blood-processing and storage centres. And at last week's press briefing, Qi acknowledged China's need for more international assistance in combating the problem. This followed an agreement on 28 June with the United States to collaborate in AIDS prevention and research. Qi also said that China is considering ways to step up the production of medicine for treating AIDS.

"The Ministry of Health is making a lot of effort and has many interesting pilot programmes," says Siri Tellier of the United Nations Population Fund, who headed the group that produced the UNAIDS report. "And they are becoming increasingly open and frank."

But China is still sending out mixed signals. The UNAIDS report accused it of "discrimination, stigma, fear, lack of transparency, and the promotion of information that leads to ignorance and unsafe practices". Xiao Qiang, executive director of New York-based Human Rights in China, brands the treatment of Wan and others as "outrageous".

Such harassment does not necessarily reflect official Chinese policy, some observers say. "The government's programmes are not implemented in a consistent fashion," says Tellier.

" www.unaids.org/whatsnew/newadds/ AIDSchina2001update.pdf

\title{
Patent office plan to beat its backlog elicits cool response
}

\section{Kendall Powell, Washington}

Concern is growing among university and industry officials that proposed reforms at the US Patent and Trademark Office will not solve the office's problems - and may even degrade the quality of the patents it issues.

In response to a request by Congress, James Rogan, the patent office's director, has developed a five-year plan to clear the office's patent backlog. The strategy includes increasing fees, and farming out patent searches - which track down existing patents and other information relevant to an application - to private contractors.

But critics say that the problems could be better addressed if Congress stopped diverting the office's existing fee income to other projects - since 1992, Congress has siphoned off $\$ 672$ million in patent fees and allowed it to hire the examiners it needs.

"I'm encouraged by the patent office's recognition of its problems," says James Stoffel, chief technical officer at Eastman Kodak in Rochester, New York. "But I'm frightened by these first steps." He and other industry leaders are concerned at the plan's reliance on untested outside contractors.

Last year, Congress told the office to produce a plan to tackle the existing backlog of 400,000 patent applications and to cut the average of two years it takes to issue a patent.

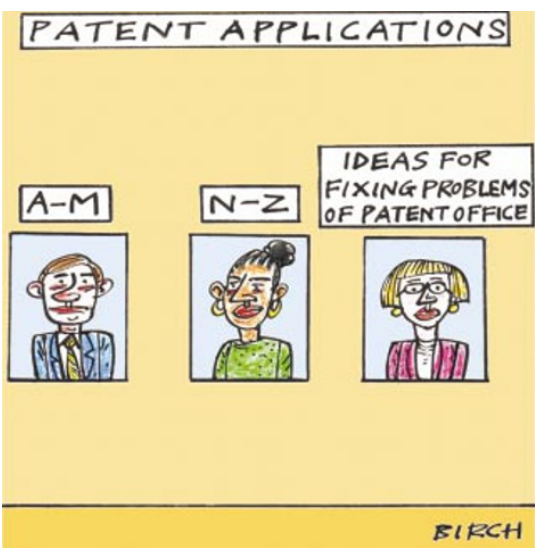

On 27 August, Jon Dudas, deputy director of the patent office, briefed a National Academy of Sciences meeting on the plan. It includes hiring 3,000 more examiners by 2008, although the office previously estimated that it actually needs 5,500 more. The office also wants to raise its fees by up to $67 \%$ next year.

Charles Garris, a mechanical engineer at George Washington University in Washington DC and a registered patent agent, says that the answer is to hire more examiners. "The rate-determining step of any process is the slowest element," Garris says. "In this process, it's the very time-consuming step of reading and understanding the applications."

\section{India's scientists agonize over fall in publication rate}

\section{K. S. Jayaraman, New Delhi}

India has been eclipsed by China as the largest scientific power in the developing world, and is set to fall behind other, far smaller nations, according to an assessment of its scientific productivity.

Subbiah Arunachalam, a science analyst at the M. S. Swaminathan Research Foundation in Chennai, revealed the troubling statistics in the Indian journal Current Science (83, 107-108; 2002). He tracked India's publishing record for the period 1980-2000 based on data from the yearly Science Citation Index issued by the Philadelphia-based company ISI.

The total number of papers published by Indian scientists in the journals tracked by ISI for the index fell slightly, from 14,983 in 1980 to 12,127 in 2000, Arunachalam found. But China's output leapt from 924 to 22,061 for the same period, and both South Korea and Brazil expanded their output rapidly (see graph).

In 1973, Arunachalam says, India was the eighth-largest producer of scientific papers in the world, and accounted for nearly half of the developing world's total output of papers. By 2000, it had slipped back to fifteenth in the world ranking.

The analysis has prompted a fresh bout of soul-searching among India's scientific leaders. "Unless we do something serious, I am afraid that we will soon become a thirdrate country in science," says C. N. R. Rao, a Bangalore-based chemist and former government adviser who now heads the Third World Academy of Sciences, based at Trieste, Italy.

"All indicators suggest that scientific output is on the decline," agrees P. Balaram, head of biological sciences at the Indian Institute of Science in Bangalore. He attributes the problem to the universities, which he says are suffering from "political interference, diminishing resources, declining faculty quality and deterioration of the academic ambience".

The analysis is particularly depressing for India as between 1980 and 2000, the number of universities grew from 128 to 231, and research and development expenditure rose substantially.

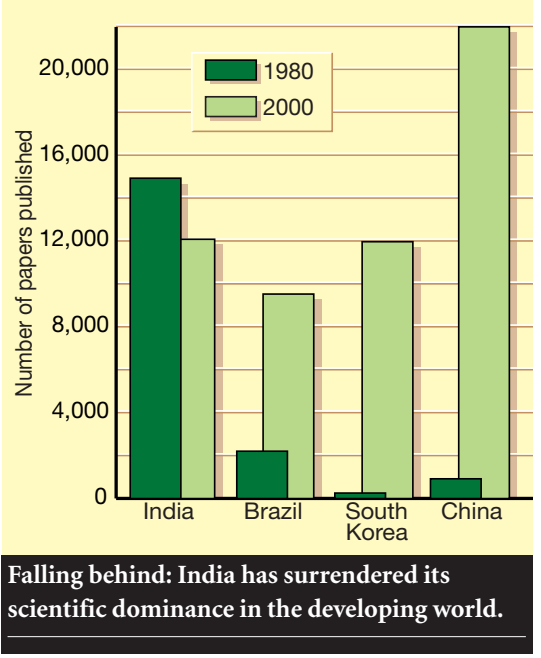

